NBER WORKING PAPER SERIES

\title{
WHAT ARE THE COSTS OF MEETING DISTRIBUTIONAL OBJECTIVES FOR CLIMATE POLICY?
}

\author{
Ian W.H. Parry \\ Roberton C. Williams III \\ Working Paper 16486 \\ http://www.nber.org/papers/w16486 \\ NATIONAL BUREAU OF ECONOMIC RESEARCH \\ 1050 Massachusetts Avenue \\ Cambridge, MA 02138 \\ October 2010
}

We are grateful to Don Fullerton, Bill Randolph, an anonymous referee, and participants in the ChicagoRFF-Illinois Symposium on Distributional Aspects of Energy and Climate Policy for helpful comments and suggestions. And we thank Fanqing Ye for her excellent research assistance. The views expressed herein are those of the authors and do not necessarily reflect the views of the National Bureau of Economic Research.

NBER working papers are circulated for discussion and comment purposes. They have not been peerreviewed or been subject to the review by the NBER Board of Directors that accompanies official NBER publications.

(C) 2010 by Ian W.H. Parry and Roberton C. Williams III. All rights reserved. Short sections of text, not to exceed two paragraphs, may be quoted without explicit permission provided that full credit, including $(\odot)$ notice, is given to the source. 
What Are the Costs of Meeting Distributional Objectives for Climate Policy?

Ian W.H. Parry and Roberton C. Williams III

NBER Working Paper No. 16486

October 2010

JEL No. H22,H23,Q48,Q54,Q58

\begin{abstract}
$\underline{\text { ABSTRACT }}$
This paper develops an analytical model to quantify the costs and distributional effects of various fiscal options for allocating the (large) rents created under prospective cap-and-trade programs to reduce domestic, energy-related $\mathrm{CO} 2$ emissions. The trade-off between cost effectiveness and distribution is striking.

The welfare costs of different policies, accounting for linkages with the broader fiscal system, range from negative $\$ 6$ billion/year to $\$ 53$ billion/year in 2020, or between minus $\$ 12$ to almost $\$ 100$ per ton of $\mathrm{CO} 2$ reductions! The least costly policy involves auctioning all allowances with revenues used to cut proportional income taxes, while the most costly policies involve recycling revenues in lump-sum dividends or grandfathering emissions allowances. The least costly policy is regressive, however, while the dividend policy is progressive, and grandfathering permits is both costly and regressive. A distribution-neutral policy entails costs of $\$ 18$ to $\$ 42$ per ton of $\mathrm{CO} 2$ reductions.
\end{abstract}

\title{
Ian W.H. Parry
}

Resources for the Future

1616 P Street, NW

Washington, DC 20036

parry@rff.org

Roberton C. Williams III

Department of Agricultural and Resource Economics

University of Maryland,

Symons Hall

College Park, MD 20742

and NBER

rwilliams@arec.umd.edu 


\section{Introduction}

One of the most important issues in the design of domestic, market-based climate policy is what to do with the rents or revenues created under cap-and-trade or emissions tax systems. ${ }^{1}$ How these policy rents are allocated and used critically affects not only the distributional impacts of the policy, but also its overall cost-effectiveness.

There are many ways to allocate policy rents. One is to grandfather allowances in a capand-trade system, that is, give them away free to existing sources, typically based on their historical emission rates. The main motivation for this approach is political-providing compensation for producers affected by the regulation may make it easier to move legislation forward. Almost all of the allowances in the US program to cap $\mathrm{SO}_{2}$ emissions from power plants were given away for free and similarly in the initial phases of the European Union's $\mathrm{CO}_{2}$ trading program. However, more recent European and US federal climate initiatives have moved away from full grandfathering, as it is widely appreciated that this approach substantially overcompensates emitters for their compliance costs. ${ }^{2}$

More recently, the distributional concern in the United States has been on the household side, particularly insulating low-income households from the prospective increase in energy prices from climate policy. Some proposals involve granting free allowances to local distribution companies with the expectation that the value of these allowances will be rebated to households in the form of lower electricity bills. Another approach that has recently gained traction is known as "cap-and-dividend", which involves a cap-and-trade program with full allowance auctions with all the revenue returned in equal lump-sum transfers for all individuals. An argument for this approach is that all individuals have equal ownership rights to the environment and therefore proceeds from charging for use of the environment should be shared equally.

A key drawback of both of these approaches is that they forgo the potentially large efficiency gains from using allowance auction revenues to cut other distortionary taxes. Personal

\footnotetext{
${ }^{1}$ Other key issues include the overall stringency of the policy, its sectoral coverage (including provisions for emission offsets), whether cap-and-trade should include price stabilization mechanisms, and to what extent supplementary instruments are warranted to address other possible market failures (e.g., technology spillovers). For a general discussion of these issues see, for example, Aldy et al. (2010).

${ }^{2}$ Power companies in the European Union earned large windfall profits when the $\mathrm{CO}_{2}$ cap was first introduced (e.g., Sijm et al., 2006). At least for a moderately scaled $\mathrm{CO}_{2}$ permit system, only about 15-20 percent of allowances are needed to compensate energy intensive industries for their loss of producer surplus, so the huge bulk of the allowances could still be auctioned (e.g., Bovenberg and Goulder, 2001, Smith et al., 2002).
} 
income and other taxes distort capital and labor markets by depressing net factor returns. They also distort household consumption decisions by allowing exemptions or deductions for particular types of spending (e.g., employer medical insurance). Therefore, using revenues to lower the rates of these distortionary taxes produces gains in economic efficiency that can substantially lower the overall welfare costs of climate policy (though this approach may do little to help with distributional objectives). In fact, without this counteracting revenue-recycling effect, the welfare costs of market-based climate policies are substantially higher in the presence of distortionary taxes, because those distortions raise production costs and product prices, and thereby lower real factor returns and factor supply (e.g., Goulder et al., 1999, Fullerton and Metcalf, 2001).

To date, no climate bills have been introduced in the US Congress that would use policy revenues to reduce marginal income tax rates, though some include uses that would have similar effects. ${ }^{3}$ Moreover, considering this case helps clarify the quite striking trade-offs involved in allocating climate policy rents.

In this paper, we develop and parameterize an analytical general-equilibrium model that synthesizes two different strands in the literature on domestic climate policy, one focusing on the cost-effectiveness of alternative market-based policies in a homogeneous agent framework and the other that looks at distributional effects in multi-agent models but with no attention to efficiency. While some of our results - such as the low cost-effectiveness of cap-and-dividend and grandfathered permits - have been recognized for some time, our analysis offers a more complete picture of efficiency/distributional trade-offs than can be gleaned from prior literature. ${ }^{4}$

\footnotetext{
${ }^{3}$ The Waxman-Markey, bill for example, devotes a portion of revenue to deficit reduction. If that deficit reduction would otherwise have been accomplished by raising marginal rates, then this would have the same effect as lowering marginal rates. In addition, a bill sponsored by Rep. Larson (HR 1337) would have used revenues to exempt a portion of income from payroll taxes. While this form of recycling would increase the return to labor force participation it would be less efficient than cutting marginal income tax rates. The latter would also increase effort on the job and reduce the bias towards tax-preferred spending. $\mathrm{CO}_{2}$ taxes which are largely revenue neutral have been implemented in British Columbia and in Scandinavian countries, though a tax proposal for France (with very limited coverage) was recently ruled unconstitutional.

${ }^{4}$ Prior analyses by Burtraw et al. (2009), Dinan and Rogers (2002), and Parry (2004) have studied the distributional impacts of various options for recycling climate policy revenues through the tax system. And many papers have been written on the linkages between environmental policies and the broader tax system and how these affect the overall costs of policy (see, for example, Goulder et al., 1999, Fullerton and Metcalf, 2001, Bovenberg and Goulder, 2002, and Schöb, 2006, among many others).

Our analysis is more than just the sum of findings from these two literatures, however. Most importantly, the efficiency and distributional results come from the same model, and thus are directly comparable. This model has several additional advantages. Unlike in most prior literature we account for broader distortions of the tax
} 
Our analysis considers three bounding cases for rent allocation and use under cap-andtrade systems. These include full grandfathering of allowances; full auction of allowances with revenues returned in lump-sum-transfers; and full auctions with revenues recycled in equal, proportionate cuts in marginal income taxes across all household groups. We also consider a "distribution neutral" policy where the tax and benefit system is adjusted to neutralize any distributional effects of the cap-and-trade policy on households, leaving the overall policy change neither progressive nor regressive. Policymakers are more likely to choose combinations of the bounding cases studied here, rather than using 100 percent of rents for one purpose alone, however the implications of these combinations are easily inferred by taking the appropriate weighted averages of our bounding cases. Furthermore, although our discussion is couched in terms of cap-and-trade, each cap-and-trade variant has an emissions tax counterpart in our analysis. $^{5}$

New revenue sources might be used in many ways other than those studied here. These run the gamut from program enhancing measures like clean technology programs, incentives for energy efficiency, and capacity investments to facilitate adaptation to climate change, to general increases in public spending and federal deficit reduction. However, it is difficult to make general statements about the potential efficiency implications from these broader alternatives for revenue use, without specific evidence on the benefit and costs of the spending measures, accounting for possible market failures that they might address. Even the effects of deficit reduction are opaque, as it is unclear whether lower debt burdens for future generations will lead to lower taxes or more public spending.

system beyond those in factor markets, so we can integrate empirical findings from recent public finance literature on the taxable income elasticity (see below). Furthermore, our distributional analysis takes into account implicit burdens on households from the changes in deadweight loss from the broader fiscal system. Moreover, we account for inflation indexing of the tax/benefit system, which provides some (albeit limited) automatic adjustment to higher energy prices. In addition, the type of multi-agent model used here is needed to avoid aggregation bias when households face different tax rates, benefit differently from revenue-recycling schemes, and have different behavioral responses to tax changes. Finally, the distribution-neutral approach described below has not previously been analyzed in the context of carbon policy.

${ }^{5}$ For example, a carbon tax with revenues returned in lump-sum transfers to firms in proportion to their historical emissions would be equivalent to cap-and-trade with grandfathered allowances. The tax and cap-and-trade approaches would differ if our analysis were extended to incorporate uncertainty over future emissions abatement costs (e.g., Pizer, 2003). 
We find that the allocation of rents under cap-and-trade (or use of revenues under carbon taxes) can have huge efficiency and distributional consequences for carbon policy, effects that can be much larger than the direct effects of the carbon policy itself.

Within the range of options we consider, the direct cost of reducing $\mathrm{CO}_{2}$ emissions to $9 \%$ below business-as-usual levels in the year 2020 is \$9 billion (all figures are in year 2007 ). However, the overall welfare costs of different policies, taking into account linkages with the broader fiscal system, ranges from negative $\$ 6$ billion/year to $\$ 53$ billion/year. In terms of average cost of $\mathrm{CO}_{2}$ reductions this is a huge range - from minus $\$ 12$ to almost $\$ 100$ per ton.

The distribution of that cost ranges from highly progressive (with the bottom two income quintiles bearing a negative burden) to highly regressive (with the top two quintiles bearing a negative burden). There are stark trade-offs between cost-effectiveness and distribution in the design of market-based climate control policies. A cap-and-dividend approach makes carbon policy more progressive at the expense of dramatically raising the overall cost, and conversely, using revenue to fund a proportional income tax cut lowers overall cost but leads to a regressive distribution of those costs. A distribution-neutralizing tax change represents a middle ground for both efficiency and distributional effects. Cap-and-trade with grandfathered allowances performs poorly on both cost and distributional grounds, though it may reduce industry opposition and thus be more politically feasible.

The rest of the paper is organized as follows. Section 2 develops our analytical framework and key formulas for the efficiency cost and distributional burden of different policies. Section 3 describes the model parameterization. Section 4 presents the main quantitative findings and sensitivity analysis. Section 5 offers concluding remarks.

\section{Analytical Framework}

\section{A. Model Assumptions}

We use a long run, comparative static model with multiple agents, each representing an average over all households within a particular income class. Households choose consumption of general goods, products that are energy intensive, products that receive favorable treatment from the tax system, and labor supply. The government prices carbon dioxide $\left(\mathrm{CO}_{2}\right)$ emissions, through a cap-and-trade system, which in turn drives up energy costs and product prices in 
general. Rents created by climate policy may accrue to the private sector (e.g., through free allowance allocation) or to the government. In the latter case, revenues are used to adjust the income tax and transfer system.

(i) Household utility. We divide households into 5 equal-sized income groups, indexed by $i$, where $i=1$ and 5 denote the lowest and highest income quintiles, respectively. Each group is modeled as a single representative household, with the utility function:

$$
u_{i}\left(X_{i E}, X_{i F}, X_{i C}, L_{i}, G^{P U B}\right)
$$

$X_{i E}$ denotes consumption of an aggregate of goods whose production or use is energy intensive (e.g., electricity-using durables, auto travel, home heating fuels). $X_{i F}$ is consumption of goods that are favored through the broader tax system, such as employer-provided medical insurance or owner-occupied housing. $X_{i C}$ is an aggregate of all other (non-energy-intensive, non-tax-favored) goods. $L_{i}$ is work effort, implicitly combining labor force participation rates and average hours worked on the job by households in that group. $G^{P U B}$ is government spending on public goods, which is fixed, and is included only to scale income tax rates to their observed levels. $u_{i}$ is quasiconcave, twice differentiable, decreasing in labor supply, and increasing in all other arguments.

(ii) Household budget constraint. The household budget constraint is given by:

$$
\sum_{j} p_{j} X_{i j}=I_{i}
$$

where $j=E, F, C$ indexes the three goods and $p_{j}$ is the market price of good $j$.

The tax and transfer system, reflecting state and federal personal income taxes, employer and employee payroll taxes, and sales taxes, minus government transfers, is represented as a piecewise-linear function with five segments and each of the five income groups falling on a different segment. For simplicity, we assume that any policy-induced changes in taxable income will be sufficiently small that no group will move to a different segment of the tax schedule. Under this assumption, the tax schedule group $i$ faces is equivalent to a linear tax with rate $t_{i}$ and intercept $-G_{i}$ (which can be found by extending the relevant segment of the piecewise-linear tax schedule out to a point with zero pre-tax income). Disposable income $\left(I_{i}\right)$ consists of taxable income $\left(\Gamma_{i}\right)$, net of taxes paid on that income. This gives 


$$
I_{i}=\left(1-t_{i}\right) \Gamma_{i}+G_{i}
$$

Taxable income consists of the wage $w_{i}$ times labor supply, plus lump-sum net-of-tax profit income $\pi_{i}$, less spending on tax-favored goods. Profit income accrues to households via their ownership of firms and reflects any producer rents created by cap-and-trade policy.

$$
\Gamma_{i}=w_{i} L_{i}+\pi_{i}-p_{F} X_{i F}
$$

The (pre-existing) tax system causes two sources of distortion. First, it distorts labor supply by depressing the returns to work effort. Second, it creates a bias towards tax-preferred spending. The combined effect of carbon policies on these two distortions can be summarized by changes in taxable income. ${ }^{6}$

(iii) Production, $\mathrm{CO}_{2}$ emissions, prices and rents. All goods are produced under constant returns to scale under perfect competition (hence there are no pure profits in the absence of carbon policy). Market prices of goods, which implicitly incorporate any energy costs associated with their use, are determined by:

$$
p_{j}=\rho_{j} p_{H}+\beta_{j}
$$

Here $\varrho_{j}$ is the energy intensity of $\operatorname{good} j$, where $\rho_{E}>\rho_{C}, \rho_{F} ; p_{H}$ is the price of energy; and $\beta_{j}$ is a parameter representing non-energy costs. ${ }^{7}$

The price of energy is determined as follows

$$
p_{H}=c\left(z^{0}-z\right)+\tau z+p_{H}^{0}
$$

where $z$ is $\mathrm{CO}_{2}$ emissions per unit of energy, $c($.) is a positive, convex abatement cost function $(c(0)=0)$ and a superscript 0 denotes the initial value of a variable (prior to the introduction of carbon policy). A reduction in $z$ represents a switch to lower carbon but more expensive fuels in energy production (e.g., a switch from coal to renewables or nuclear power). Emissions are priced at rate $\tau$, which reflects the allowance price. Our assumptions also imply that emissions

\footnotetext{
${ }^{6}$ We implicitly assume that that tax preferences do not address any market failures, and thus are purely distortionary.

${ }^{7}$ For simplicity $\varrho_{j}$ is taken as fixed though relaxing this would not affect the results, given our parameterization below.
} 
prices and abatement costs will be fully passed through into energy prices. As discussed below, this assumption is debatable, although it does not affect the key focus of our paper, which is the trade-off between costs and distributional goals in allowance allocation.

Economy-wide $\mathrm{CO}_{2}$ emissions, $Z$, are the product of the emissions intensity of energy and energy use aggregated over all products and households:

$$
Z=z \sum_{j} \rho_{j} \sum_{i} X_{i j}
$$

For simplicity, we focus on a policy covering $\mathrm{CO}_{2}$ only, which accounts for about 80 percent of total US greenhouse gases. In addition, the (energy-related domestic) $\mathrm{CO}_{2}$ reductions, and the emissions price, are approximately consistent with those projected under recent climate legislation. ${ }^{8}$

Profit income to household group $i$ is given by:

$$
\pi_{i}=\theta_{i} \phi \tau Z
$$

$\theta_{i}$ is the fraction of (economy-wide) energy capital owned by household group $i$ (implicitly, this includes both retirement and non-retirement bond and stockholdings), where $\Sigma_{i} \theta_{i}=1$ and $\theta_{i}$ is larger for higher income groups. $\phi$ is the portion of policy rents that are left in the private sector, as opposed to accruing to the government in revenue. $\phi=0$ represents a cap-and-trade system with full allowance auctions. $\phi=1$ represents a system with 100 percent free allowance allocation to energy firms, where entire policy rents $\tau Z$ are reflected in higher firm equity values and stockholder wealth, and such income is not taxed. Intermediate cases might represent partial taxation of allowance rents or partial auctioning of allowances. Outcomes for these cases are easily inferred by taking weighted averages of the results below.

(iv) Government Constraints and Policy. The government is subject to the budget constraint

$$
G^{P U B}=\sum_{i} t_{i} \cdot \Gamma_{i}-\sum_{i} G_{i}+(1-\phi) \tau Z
$$

\footnotetext{
${ }^{8}$ Although under current legislation firms may purchase offsets in other domestic sectors (e.g., forestry and agriculture) and in other countries we do not count those as part of the emission reduction, nor do we include the deadweight losses (in other sectors or countries) associated with those broader reductions. A key concern with offsets is the difficulty of verifying whether or not these broader emission reductions would have occurred anyway, and whether they might be negated through increased emissions elsewhere (e.g., slowed deforestation in one country might accelerate deforestation in other countries through a rise in global timber prices).
} 
This constraint requires that spending on public goods equals revenue from the income tax system, plus revenue from the carbon policy.

Following the introduction of a carbon policy, the intercept terms in the tax schedule are adjusted as follows:

$$
G_{i}=G_{i}^{0} \bar{p}+\hat{G}_{i}, \quad \bar{p}=\sum_{j} \mu_{j} p_{j}, \quad \mu_{j}=\frac{\sum_{i} X_{i j}^{0}}{\sum_{i j} X_{i j}^{0}}
$$

where we have normalized all initial product prices to unity. $\bar{p}$ is the general price level, a weighted average of market prices where the weight $\mu_{j}$ is the (initial) share of economy-wide spending (or consumption) on good $j$.

According to (9), the nominal tax schedule is automatically "inflation-indexed" to reflect increases in the general price level (this implies that marginal and average tax rates depend on real income). In addition, some schemes devote a portion of the new revenues to making the policy more progressive, which implies an additional adjustment $\hat{G}_{i}$ to transfer payments.

More specifically, we consider four bounding cases for the allocation/use of policy rents (each defined for the same emissions reduction/emissions price):

Proportional income tax cut $\left(\phi=0, \hat{G}_{i}=0\right)$. In this case, all policy rents go to the government and, after indexing the nominal tax schedule, all other revenue is used to finance an equal reduction in the marginal tax rate faced by all income groups, that is, $d t_{i} / d \tau=d t / d \tau<0, \forall i$.

Cap and dividend $\left(\phi=0, \hat{G}_{i}=\hat{G}>0\right)$. For this policy, allowances under a cap-and-trade policy are fully auctioned with revenues (after indexing) returned in equal lump-sum transfers to households.

Grandfathered permits $\left(\phi=1, \hat{G}_{i}=0\right)$. Here all allowances are given away for free and all policy rents accrue to households through their ownership of firms. (Again, we abstract from taxation of rents).

Distribution-neutral $\left(\phi=0, \hat{G}_{i} \neq 0\right)$. Whereas the tax change in the proportional tax cut case entails the same change to all marginal tax rates, the distribution-neutral case requires changing marginal income tax rates by different amounts at different points in the income distribution, in 
order to equalize the net burden as a percentage of income across all quintiles. ${ }^{9}$ The efficiency gains from revenue recycling are smaller in the distribution-neutral case than in the case with proportional tax rate reductions. This occurs primarily because marginal rates fall by less in this case than in the proportional tax cut case. Cutting tax rates on low income groups leads to a relatively large drop in tax revenue, because all higher income groups also benefit from the rate reductions for the lower income brackets. Consequently, a tax cut disproportionately targeted at lower income groups will yield a smaller reduction in marginal rates than would a proportional tax cut.

In all four cases we assume that any indirect revenue losses are made up through equal, proportionate adjustments to all marginal income tax rates. ${ }^{10}$ These losses stem from reductions in taxable income as households, for example, reduce labor supply in response to lower real wages as higher energy prices drive up the general price level.

One noteworthy limitation of our analysis is that the model does not capture distortions from taxes on capital income. In this regard we mischaracterize, though perhaps only moderately, the efficiency gains from, and the incidence of, proportional cuts in marginal income taxes. More generally, incorporating taxes on capital income would admit a wider range of possibilities for changes in the taxation of personal and corporate income in response to recycling revenue from allowance sales.

\section{B. Formulas for Efficiency Costs and Distributional Burdens of Carbon Policies}

Here we go straight to the main formulas of interest. These are general expressions for the components of the efficiency costs and distributional burdens of carbon policies, and how those components vary under the allocation/recycling options just described. The formulas below are (reasonable) approximations given the scale of emission reductions considered and would be

\footnotetext{
${ }^{9}$ This is similar to the approach taken in Williams (2009a and 2009b) when considering a distribution-neutralizing tax change in other policy contexts, but while those papers assume a continuous income distribution, this paper works with a discrete distribution made up of five quintiles. The approach in those papers in turn draws on earlier work by Kaplow (2004).

${ }^{10}$ Alternatively, we could assume that indirect revenue losses are deducted from the amount of revenue returned in transfers under cap-and-trade, or the size of the allowance giveaway under grandfathered permits, with significant implications for distributional incidence. However, our assumption is more in keeping with actual policy proposals (not least, given the difficulty of accurately projecting indirect revenue losses).
} 
exact if demand and marginal abatement cost curves were linear over the relevant range. Derivations for the formulas are provided in the Appendix.

(i) Efficiency costs. The (approximate) efficiency cost of a carbon policy that reduces aggregate $\mathrm{CO}_{2}$ emissions by an amount $\Delta Z=Z^{0}-Z$, with associated emissions price $\tau$, can be decomposed into the following four components:

$$
\begin{aligned}
& W C^{H T}-W G^{R R}+W C^{T I}+W C^{I N C} \\
& W C^{H T}=\frac{1}{2} \cdot \tau \cdot \Delta Z, \quad W G^{R R}=M E B \cdot\left\{(1-\phi) \tau E-\sum_{i} \Delta G_{i}\right\} \\
& W C^{T I}=(1+M E B) \cdot \sum_{i} t_{i} \frac{\partial \Gamma_{i}}{\partial \bar{p}} \Delta \bar{p}=(1+M E B) \cdot \sum_{i} \alpha_{i}^{I} t_{i} \varepsilon_{i}^{\bar{p}} \tau\left(Z+\frac{\Delta Z}{2}\right), \\
& W C^{I N C}=-(1+M E B) \cdot \sum_{i} t_{i} \frac{\partial \Gamma_{i}}{\partial G_{i}}\left(\Delta G_{i}+\pi_{i}\right)=-(1+M E B) \cdot \sum_{i} \alpha_{i}^{I} t_{i} \varepsilon_{i}^{I} \frac{\Gamma_{i}}{I_{i}} \Delta G_{i}
\end{aligned}
$$

where

$$
\begin{gathered}
M E B=\frac{-\sum_{i} t_{i} \frac{\partial \Gamma_{i}}{\partial t_{i}}}{\sum_{i} \Gamma_{i}+\sum_{i} t_{i} \frac{\partial \Gamma_{i}}{\partial t_{i}}}=\frac{\sum_{i} \alpha_{i}^{\Gamma} \varepsilon_{i}^{t} \frac{t_{i}}{1-t_{i}}}{1-\sum_{i} \alpha_{i}^{\Gamma} \varepsilon_{i}^{t} \frac{t_{i}}{1-t_{i}}}, \\
\varepsilon_{i}^{t}=\frac{\partial \Gamma_{i}}{\partial\left(1-t_{i}\right)} \frac{1-t_{i}}{\Gamma_{i}}, \quad \varepsilon_{i}^{\bar{p}}=\frac{\partial \Gamma_{i}}{\partial \bar{p}} \frac{\bar{p}}{\Gamma_{i}}, \quad \varepsilon_{i}^{I}=\frac{\partial \Gamma_{i}}{\partial I_{i}} \frac{I_{i}}{\Gamma_{i}}, \quad \alpha_{i}^{\Gamma}=\frac{\Gamma_{i}}{\sum_{i} \Gamma_{i}}, \quad \alpha_{i}^{I}=\frac{\Gamma_{i}}{\sum_{i} I_{i}}
\end{gathered}
$$

Beginning with (10b), $\varepsilon_{i}^{t}, \varepsilon_{i}^{\bar{p}}$, and $\varepsilon_{i}^{I}$ denote three different taxable income elasticities for household $i$ defined with respect to changes in marginal tax rates, changes in the general price level, and changes in (taxable) household income, respectively. $\alpha_{i}^{\Gamma}$ is the share of household group $i$ 's taxable income in economy-wide income.

$M E B$ is the marginal excess burden of taxation, the efficiency cost of raising an extra dollar of revenue through a proportionate increase in marginal income taxes. The numerator of $M E B$ is the efficiency loss from an incremental increase in the marginal income tax for group $i$, aggregated over all households. The efficiency loss for group $i$ is the induced reduction in taxable income (reflecting both reductions in labor supply and increases in tax-preferred spending) times the marginal tax rate. The denominator of the $M E B$ is the extra revenue from the tax increase, summed over all households. Alternatively, the $M E B$ can be expressed as a function 
of the weighted sum of taxable income elasticities (with respect to tax rates) for different household groups, with weights equal to the households' share in economy-wide taxable income. Note that, according to the way we have defined it in (10b), behavioral responses underlying the $M E B$ are uncompensated.

In equation (10a), the first component of the welfare cost, $W C^{H T}$, corresponds to the Harberger triangle under the economy-wide marginal abatement cost curve. This curve represents the envelope of other marginal abatement cost curves for each margin of behavior for reducing emissions-reducing emissions per unit of, and reducing overall consumption of, energy-intensive products. ${ }^{11}$ The Harberger triangle is the same under all four policy scenarios.

The second component in (10a), $W G^{R R}$, termed the revenue-recycling effect (e.g., Goulder 1995), is the efficiency gain that results to the extent that revenues are used to reduce marginal income taxes. This component is the product of the $M E B$ and the amount of revenue recycled in this fashion, where the latter is the policy rents retained by the government less what is spent on transfer payments and indexing.

The third welfare cost component, $W C^{T I}$, is the tax-interaction effect. In most prior work this referred to the welfare loss from the reduction in labor supply as policy-induced increases in the general price level reduced the real return to work effort (e.g., Goulder 1995). The welfare loss was the change in labor earnings, multiplied by the labor tax distortion, and multiplied by $1+M E B$, as lost labor tax revenues must be made up through higher (distortionary) taxes to maintain budget balance. In these models, the change in labor earnings depends on both the responsiveness of labor supply to higher prices, and the loss of worker surplus from the price increase. The latter is (approximately) equal to allowance rent plus the Harberger triangle under the marginal abatement cost curve, and corresponds to $\tau(Z+\Delta Z / 2)$ in our formula for $W C^{T I}$. However, in our case the tax-interaction effect is measured with respect to changes in taxable income, in response to higher product prices, rather than labor earnings, and hence it is the taxable income, rather than labor supply, elasticity that appears in our formula. The taxinteraction effect (as defined here) is also constant across different policies.

\footnotetext{
11 These marginal cost curves all come out of the origin given that our model abstracts from other distortions affecting the production and use of energy, such as fuel taxes, automobile congestion, and non-competitive pricing of electricity.
} 
Our expression for $W C^{T I}$ embeds a number of simplifying assumptions that might, to some degree, be open to question (see the Appendix). One is that we assume all goods are equal substitutes for leisure and therefore not deserving of any Ramsey tax or subsidy from an optimal tax perspective. In the absence of evidence to the contrary however, this seems a reasonable, neutral assumption. Another simplification is that compliance costs are fully passed forward into higher prices. To the extent, for example, that compliance costs come at the expense of inframarginal rent earned on base load power generation, the price effect and tax-interaction effect will be weaker. ${ }^{12}$ In short, the reader should bear in mind that the absolute value of the taxinteraction effect is difficult to pin down accurately, though this is not relevant for the cost/distributional tradeoffs involved in allocating cap-and-trade rents, which is the main focus of our paper.

The final component of welfare cost, $W C^{I N C}$, reflects efficiency losses from the reduction in taxable income in response to higher lump-sum income - through higher government transfers and/or profit income. This largely reflects a reduction in labor supply as households take more leisure, which is a normal good.

(ii) Distributional burden. The distributional burden of the emissions pricing policy on household group $i$, relative to income, is fairly straightforward and can be approximated by (see the Appendix for derivations):

$$
\sum_{j} \frac{\Delta p_{j}^{0} X_{i j}^{0}}{I_{i}^{0}}+\frac{\Delta G_{i}+\pi_{i}}{I_{i}^{0}}+\frac{\Delta t_{i} \Gamma_{i}}{I_{i}^{0}}
$$

The first terms reflects the (first order) consumer surplus loss from the induced increase in energy prices. The second term picks up possible benefits from dividends and rent income through stock ownership under grandfathered permits. And the third term reflects gains from reductions in marginal tax rates. The efficiency consequences from the revenue-recycling, taxinteraction, and income effect on labor supply are all included in the distributional analysis, through overall changes in marginal income tax rates, in the third term. We omit the Harberger

\footnotetext{
12 The price pass through may also be imperfect in states that retain cost-of-service regulation for power generation - in this case, utilities receiving free allowance allocations cannot pass forward the opportunity cost of such allowances in higher generation prices. See Parry (2005) for more discussion of these issues.
} 
triangle from the distributional analysis, as this is small relative to the first order loss of surplus to households from higher energy prices.

\section{Parameterization of the Model}

Our baseline parameter assumptions are summarized in Table 1. We focus on projections for year 2020. All monetary figures are expressed in year 2008 dollars (or thereabouts). Income distribution. To obtain the income distribution we use data from the Consumer Expenditure Survey (CEX) for years 2007 and 2008, for households that completed their year in the survey panel during 2008. ${ }^{13}$ As is standard in incidence analysis we divide households into quintiles in two different ways: based on their pre-tax annual income and based on their total consumption. ${ }^{14}$ To the extent that households are able to smooth consumption over time, the consumption-based measure will more accurately reflect lifetime income. Distributional differences are more muted when measured based on consumption quintiles than based on income quintiles.

Under either measure, quintile 1 is the lowest 20 percent of income earners, quintile 2 the next lowest 20 percent, and so on. For simplicity, we assume the real income and real consumption of each household group grows at the same 1.5 percent annual rate out to 2020. In 2020 , income per household varies from $\$ 11,307$ for the lowest income quintile to $\$ 181,626$ for the top quintile, and consumption varies from $\$ 19,253$ for the lowest consumption quintile to $\$ 126,173$ for the highest (Table 1).

Budget shares for energy-intensive goods. In the analytical model, goods are either energyintensive or non-energy intensive. In the real world and in the data, goods vary widely in their energy (and thus carbon) intensity. One could simply divide goods into energy-intensive and non-energy-intensive categories and assign all energy-intensive goods the same embodied carbon

\footnotetext{
${ }^{13}$ The CEX uses a rotating panel design: each calendar quarter, one fourth of the households in the sample are rotated out, so each household appears in the data for four quarters. To obtain a full year of data on each household that completed its time in the panel during 2008 therefore requires using data from both 2007 and 2008.

${ }^{14}$ Because income in the CEX is known to be poorly measured for low-income households, it is customary for incidence studies to drop some very low-income households to minimize the effects of that measurement problem. We follow the same approach as Grainger and Kolstad (2010), dropping households with reported income below $\$ 7,500$, but not altering the quintile cutoff levels of income and expenditure as a result of dropping those households.
} 
content and all non-energy-intensive goods a lower or zero embodied carbon content. But given the wide variation in embodied carbon across goods, this could introduce substantial inaccuracy when measuring the distributional burden of a carbon tax.

Instead, we estimate the total carbon embodied in all of the goods a household consumes, and then define the consumption of energy-intensive goods in the model to be proportional to that total. In effect, this treats consuming a particular good from the CEX as consuming some of the energy-intensive good and some of the non-energy-intensive good, with the relative proportions being determined by the embodied carbon content of that good. We take the estimates of embodied carbon for goods in the CEX from Hassett et al. (2007), who calculate those estimates based on input-output tables from the US Bureau of Economic Analysis.

Stock ownership. We calculate stock ownership by aggregating for each quintile the value of estimated market value of all stocks, bonds, mutual funds, and other such securities reported by each household in the CEX. According to this calculation, the top-income quintile owned 59.8 percent of stockholdings, while the lowest income quintile owned 2.6 percent. Stock ownership shares are assumed to be the same in 2020 as in 2007-08. ${ }^{15}$

Household tax rates and transfers. Marginal and average rates of federal and state income taxes (accounting for the earned income tax credit and child tax credits), and sales taxes, were obtained by running each household from the CEX data for 1997-1999 through the NBER's TAXSIM model, using the tax laws for those years, and then aggregating for each quintile. ${ }^{16}$ We add to these employer and employee payroll taxes (based on statutory rates) to obtain the overall income tax rates (assumed to apply in 2020) shown in Table 1. Marginal tax rates vary from 0.17 for the bottom income quintile to 0.41 for the top income quintile and average (weighted by taxable income) 0.40 .

\footnotetext{
${ }^{15}$ Ideally, we would use information on the pattern of stock ownership across energy-intensive firms (rather than all firms) to gauge the distribution of rent income under grandfathered permits. However, this is difficult to obtain given that most stocks are owned indirectly through large investment firms.

${ }^{16}$ These years pre-date the federal income tax cuts of 2001 and 2003, and thus will approximate the taxes that will apply if those tax cuts are allowed to expire (which seems increasingly likely over time, given budgetary pressures). We feel this provides a better approximation to the tax laws in 2020 than would using the 2008 tax laws. To the extent that this over- or underestimates marginal tax rates in 2020, the magnitudes of the revenue-recycling and taxinteraction effects will also be over- or underestimated.
} 
Taxable income elasticities. During the last decade, a substantial number of papers have estimated the elasticity of taxable income with respect to tax rates, both for the economy as a whole, and for high-income taxpayers. Although initial estimates of this elasticity were quite large (e.g., Feldstein 1999), more recent estimates are considerably smaller, in part reflecting better data and improved methods of controlling for non-tax factors affecting changes in taxable income. Based on a careful review of evidence for the United States and other countries, Saez et al. (2009) put the taxable income elasticity (for the economy as a whole) at 0.12 to 0.40 , with more estimates closer to the top end of this range than the bottom. ${ }^{17}$

Although we assume that all taxpayers have the same labor supply elasticity, higher income taxpayers tend to have more scope for exploiting tax preferences, so they tend to have higher taxable income elasticities. We assume taxable income elasticities with respect to tax rates vary between 0.2 for the low income quintile and 0.35 for the top income quintile, as shown in Table 1, where (weighting by household shares in taxable income) the average elasticity is 0.31 .

An increase in the general price level (in response to carbon policy) has a comparable effect on labor supply to a reduction in the real household wage - that is, households substitute leisure for work, though this is partly offset by an income effect in the opposite direction. The effect on tax-preferred spending should be small since the price of ordinary spending does not change relative to the price of tax-favored spending. ${ }^{18}$ For the same reason, the change in taxable income in response to higher lump-sum payments should be similar to the change in labor earnings. We therefore use standard values for the uncompensated labor supply elasticity, and income elasticity of labor supply, namely 0.15 and -0.2 (e.g., Blundell and MaCurdy, 1999), as proxies for $\varepsilon_{i}^{\bar{p}}$ and $\varepsilon_{i}^{I}$ for all households.

\footnotetext{
${ }^{17}$ One caveat here is that there is a slight mismatch between our representation of the taxable income elasticity and empirical estimates of that elasticity. In our model, this elasticity reflects tax-induced reductions in labor supply and shifting to tax-preferred consumption, whereas empirical studies summarize a broader range of responses including shifting to tax-sheltered saving. This mismatch (which we believe is not too important for our purposes) is due to our characterizing the income tax system as a tax on labor alone, rather than a tax on both labor and capital income.

${ }^{18}$ That is, although tax-preferred spending will fall in response to higher energy prices the resulting efficiency gain (due to offsetting the tax subsidy) is modest relative to the efficiency loss from the reduction in labor supply. This is because the "market" for tax-preferred spending is small (about 10-15 percent) relative to the labor market.
} 
Emissions reductions and prices. These are based on a policy simulation of representative climate bills reported in Krupnick et al. (2010) using a variant of the Energy Information Administration's National Energy Modeling System (NEMS). NEMS is a dynamic, economicengineering model of the economy, with considerable detail on a wide spectrum of existing and emerging technologies across the energy system. Its projections are widely used by other energy modeling groups.

Without climate policy, this model projects $\mathrm{CO}_{2}$ emissions to be about 6 billion metric tons in 2020. The electricity and transport sectors account for about 40 and 33 percent of these emissions respectively, and other sources (i.e., non electricity emissions from the industrial, commercial, and residential sectors) account for the remaining 27 percent. With climate policy, energy-related $\mathrm{CO}_{2}$ emissions are reduced by about 9 percent below business-as-usual levels in 2020 , or by 0.54 billion tons, and the allowance price is $\$ 33$ per ton of $\mathrm{CO}_{2}$ in current dollars (Krupnick et al. 2010). ${ }^{19}$ Thus, the Harberger triangle, $W C^{H T}$, is about $\$ 9$ billion and policy rents, $\tau Z$, are about $\$ 180$ billion. The carbon policy increases energy prices in our model by 7.9 percent or the general price level by 0.5 percent.

\section{Results}

\section{A. Cost Comparison}

Figure 1 shows the overall cost of imposing a carbon policy with an allowance price of $\$ 33$ per ton of $\mathrm{CO}_{2}$, under each of the four options for the use of allowance rents: a proportional income tax cut, lump sum rebates to households, free allocation of permits to firms, and a distribution-neutralizing tax cut. For this last option, the cost varies substantially based on whether the tax cut neutralizes distributional effects across income quintiles or across consumption quintiles, so these are presented separately. Note that Figure 1 provides just an estimate of policy costs: it does not incorporate any estimates of the climate benefits from lower $\mathrm{CO}_{2}$ emissions.

For each case, the figure also shows the four components of welfare cost: the Harberger triangle term (the partial-equilibrium cost, ignoring any interactions with the tax system); the

\footnotetext{
19 This policy run involves a more aggressive emission reduction target, but allows domestic and international offsets (under an intermediate assumption about the availability of such offsets). Here we assume that the same emissions price projected by this run is imposed, but is applied only to $\mathrm{CO}_{2}$ with no offsets. In either case, the reduction in domestic, energy-related $\mathrm{CO}_{2}$ should be essentially the same.
} 
revenue-recycling effect (the gain from using allowance rents to finance tax rate cuts); the taxinteraction effect (the general-equilibrium loss resulting when higher energy prices discourage labor supply); and the income effect on labor supply (a further general-equilibrium loss as the income effect from the distribution of policy rents further discourages labor supply). The Harberger triangle is the same across all the policy simulations ( $\$ 8.9$ billion a year in 2020) as is the tax-interaction effect ( $\$ 25.0$ billion). However, the revenue-recycling effect, in particular, differs across policies, as does the income effect on labor supply.

When allowance rents are used to finance a proportional income tax cut, the overall cost of the policy is $-\$ 6.4$ billion/year. This case yields a "strong" double dividend (Goulder, 1995): even ignoring the benefits of reduced carbon emissions, the cost of the policy is still negative. As discussed in Parry and Bento (2000), when certain categories of spending are tax-favored, the gains from the revenue-recycling effect are magnified (relative to a case without such tax preferences), but the losses from the tax-interaction effect are approximately unaffected. As a result, the revenue-recycling effect (a gain of $\$ 41.3$ billion) exceeds the tax-interaction effect, and by enough to more than offset the Harberger triangle. This qualitative result is different than in earlier literature that focused only on the labor market distortion caused by the tax system (e.g., Goulder, 1995). In the latter models, the revenue-recycling effect typically falls short of the tax-interaction effect and the overall costs of auctioned cap-and-trade systems (or carbon taxes) is positive, and exceeds the Harberger triangle. ${ }^{20}$

The welfare cost of the cap-and-trade policy is much higher under either the cap-anddividend or free permit allocation cases: under each of these options the cost is roughly $\$ 50$ billion a year in 2020. By giving away the permit rents, these two options give up the large gain from the revenue-recycling effect ( $\$ 41.3$ billion). In addition they produce a smaller, but still significant, loss of $\$ 6.4$ billion (under cap-and-dividend) or $\$ 11.6$ billion per year (under grandfathered permits) because the resulting lump-sum income to households reduces labor supply. This effect is stronger for the grandfathered permit case as higher income householdswho face higher marginal income tax rates-receive a disproportionately larger share of the policy rents in this case. The overall welfare cost of the cap-and-dividend and grandfathered permit polices is over five times the Harberger triangle, underscoring the bias in cost analyses

\footnotetext{
${ }^{20}$ Similarly, if tax preferences were entirely justified by market failures then the revenue-recycling effect would be smaller. In this case, the overall cost of our proportional tax cut case would be positive (roughly $\$ 15$ billion).
} 
that omit interactions with the broader tax system. ${ }^{21}$ Dividing total costs by the $\mathrm{CO}_{2}$ reduction ( 0.54 billion tons) the average cost per ton reduced is around $\$ 90$ under cap-and-trade, compared with minus $\$ 12$ in the proportional tax reduction case.

Inflation-indexing of taxes and transfers in the above policy cases requires revenue outlays of $\$ 30$ billion/year in 2020 , or one-sixth of the policy rents. The implied increase in marginal tax rates to cover this revenue loss adds $\$ 7.4$ billion/year to overall welfare costs. In the proportional income tax case this cost leads to a smaller overall gain from the revenue-recycling effect, while in the grandfathered permit and cap-and-dividend cases (which give away the entire $\$ 180$ billion of policy rents) it is reflected in a negative revenue-recycling effect. ${ }^{22}$

The overall cost of the distribution-neutral options fall between the cost under the proportional tax cut and the cost under the cap-and-dividend policy-welfare costs are $\$ 9.9$ and $\$ 22.6$ billion in the consumption-based and annual income-based cases for measuring inequality, respectively. The distribution-neutralizing tax change lowers tax rates rather than providing a lump-sum transfer, so it generates a gain from the revenue-recycling effect, which causes the overall cost to be substantially lower than the overall cost under the cap-and-dividend and grandfathered permits. However, because the tax cuts are larger for lower-income households (to offset the regressive incidence of higher energy prices), the marginal tax rate reductions and corresponding efficiency gains from revenue recycling are smaller than in the proportional tax cut case. This effect is even more pronounced when inequality is measured using annual income rather than consumption. In the former case, higher energy prices are more regressive, requiring

\footnotetext{
${ }^{21}$ These results implicitly assume that none of the permit rents are taxed under either policy option. This is very likely to be true in the cap-and-dividend case. However, in the free permit allocation case, the permit rents could well be taxed, at least in part. To the extent that these rents accrue to stocks held in taxable accounts (as opposed to retirement or other tax-sheltered accounts), they will be subject to tax. Under either policy option, if the rents are taxed, then the overall cost will be a linear combination of the cost under that policy option (which assumes that none of the rents are taxed) and the cost under the proportional tax cut (which is equivalent to a case in which all of the permit rents are taxed at a rate of 100 percent).

${ }^{22}$ Note that because the tax system is indexed such that tax rates depend on real income, the overall results - both for efficiency and distribution - do not depend on the particular normalization used for prices (i.e., the choice of numeraire). However, the decomposition of those results into "inflation indexing" and other components does depend on the price normalization. We use a price normalization that holds the pre-tax wage constant, so a rise in the price of consumer goods relative to labor shows up as an increase in the overall price level, which produces the "inflation indexing" results shown here. If instead we were to use a normalization that holds the price of consumer goods constant, that same relative price change would show up as a reduction in the pre-tax wage. In this case, there would be no revenue cost for inflation indexing, but instead there would be a reduction in income tax revenue resulting from the lower wages. Thus, the overall effect would be the same, but the decomposition of that effect between "inflation indexing" and other effects on revenue would differ.
} 
an even greater concentration of tax cuts among lower income households. Thus, the revenuerecycling gains are $\$ 15.8$ billion in this case, compared with $\$ 25.7$ billion when inequality is measured using the consumption approach.

\section{B. Distributional Effects}

Figures 2 and 3 summarize the distributional burdens of the different policies across income quintiles, based on income and consumption quintiles, respectively. Burdens are expressed as a percent of household income. In addition, the net burden is decomposed into the burden of the higher energy prices caused by the cap-and-trade program; the gain to households resulting from inflation-indexing of the tax and transfer system; any gain from reductions in marginal income tax rates; and possible gains from permit rents or lump-sum dividends. ${ }^{23}$

All policies impose the same pattern of burdens across households due to higher energy prices. This burden component falls with income-for example, the bottom quintile bears a burden of 6.0 percent when inequality is measured on an income basis, falling steadily to 1.2 percent for the top quintile. Lower income groups spend a greater fraction of their income on energy-intensive consumption. One reason for this is that energy-intensive goods make up a slightly larger share of spending for lower-income households. Another is that lower-income households spend a larger fraction of their income due to lower or even negative saving rates (on average lower income households spend more than their income). Dividing households into consumption quintiles rather than income quintiles greatly reduces this second effect, and hence the distributional burden is considerably less regressive when measured based on consumption quintiles. In this case, the bottom quintile bears a burden of 3.3 percent while the top quintile bears a burden of 1.5 percent.

Inflation-indexing of the tax and transfer system provides an automatic offset for part of the burden of the policy and again the pattern of this gain across households is the same across policy scenarios. As the prices of energy-intensive goods rise, inflation-indexing causes an increase in transfers (or decrease in taxes paid, for indexing of tax brackets and other elements of the tax system). Averaged across all households, the benefit from inflation indexing is about 0.3

\footnotetext{
${ }^{23}$ The results discussed below are broadly consistent with those in Burtraw et al. (2009) who look at the incidence of federal cap-and-trade policies under alternative revenue uses using a model with considerable disaggregation by households and region.
} 
percent of income, or about one-seventh of the average burden from higher energy prices (1.9 percent). The portion of the burden of energy prices offset by inflation indexing varies relatively little across income quintiles - for example, it offsets roughly one-seventh of the burden for the bottom quintile, about one-fifth for the middle, and one-eleventh for the top quintile. ${ }^{24}$

For the proportional income tax case (Figures $2 \mathrm{a}$ and $3 \mathrm{a}$ ), by definition the gains from the tax cut are the same for each quintile, roughly 1.7 percent of income for each group. The overall net burden under this policy as a percentage of income is highest for the bottom quintile and falls steadily as one moves up the income distribution, given that revenue-recycling does nothing to offset the regressive effect of higher energy prices. For income-based quintiles the net burden varies between 3.5 and minus 0.6 percent across the lowest and highest quintiles, while for consumption-based quintiles it varies from 1.2 to minus 0.3 percent.

For the cap-and-dividend policy (Figures $2 b$ and $3 b$ ) the distribution of the policy dividend is highly progressive, given that all households receive the same absolute cash rebate. As a result, even though the overall cost of this policy is much higher than in the proportional income tax cut case, the bottom three quintiles experience smaller net burdens under cap-anddividend. In fact, the bottom two quintiles actually have a negative net burden (under either income- or consumption-based quintiles). This illustrates the stark tradeoff between efficiency and distribution: lower-income groups are much better off under cap-and-dividend than they are under a proportional income tax cut, but the overall welfare cost of the policy is dramatically higher.

The policy with free allowance allocation to firms (Figures $2 \mathrm{c}$ and $3 \mathrm{c}$ ) does nothing to offset the regressive effect of higher energy prices - in fact the distribution of rent income is itself regressive, for the most part, given that for better off households capital is typically a larger share of their income. Comparing this case to either the proportional income tax cut or the capand-dividend case reveals no tradeoff between efficiency and distribution. Freely allocating permits to firms results in a similarly regressive distribution of net burden to the proportional income tax case, but a much higher overall cost because it fails to exploit the revenue-recycling effect. In fact, every income quintile is better off under the proportional income tax cut than

\footnotetext{
${ }^{24}$ For reasons analogous to those discussed in footnote 22, above, the net burden on each quintile is independent of the choice of price normalization. But the decomposition of that net burden into "inflation indexing" and other components does depend on the normalization.
} 
under free permits. Conversely, the cap-and-dividend case results in a much more progressive distribution of net burdens than free permits, but has a similar (even slightly lower) overall cost.

Under the distribution-neutralizing change (Figures $2 \mathrm{~d}$ and $3 \mathrm{~d}$ ) the tax change is designed to be sufficiently progressive to exactly offset the regressive burden of higher energy prices, thus making the distribution of the net burden of the policy proportional to income. This case falls between the proportional tax cut and cap-and-dividend cases, in terms of both efficiency and distribution: the overall cost is lower than under cap-and-dividend but higher than under the proportional tax cut, and the distribution of burden is less progressive than under cap-anddividend but less regressive than under the proportional tax cut.

\section{Conclusions}

The allocation and use of rents created under cap-and-trade programs (or revenues under an emissions tax) can hugely affect the overall efficiency and distributional effects of carbon policy. Within the range of options we consider for the use of revenue, in a case where the direct cost of the carbon restriction itself is $\$ 9$ billion/year in 2020 , the overall welfare cost of the policy ranges from negative $\$ 6$ billion/year to $\$ 53$ billion/year. And the distribution of that cost ranges from highly progressive (with the bottom two income quintiles bearing a negative burden) to highly regressive (with the top two quintiles bearing a negative burden).

In general, there is a clear tradeoff between efficiency and distribution. Using policy revenues to fund cuts in marginal income tax rates is highly efficient, but leads to a regressive distribution of the net burden. At the other end of the range, the cap-and-dividend approach has a far higher overall cost, but leads to a highly progressive distribution. And a distributionneutralizing tax change represents a middle ground for both efficiency and distributional effects.

This tradeoff does not hold for free permit allocation to firms in affected industries, which has both a high overall cost and regressive distribution of that cost. But this can be viewed as an efficiency-distribution tradeoff along a different dimension, addressing distributional concerns across firms in different industries rather than across households in different income groups. Thus, while this type of allocation is both inefficient and regressive, it may have more political traction.

More generally, our discussion underscores that the case for cap-and-trade without revenue recycling is more fragile than generally realized (at least for medium term levels of 
emissions controls envisioned in recent climate bills). Our calculations imply the average cost of reducing domestic, energy-related $\mathrm{CO}_{2}$ when policy rents are not used to cut distortionary taxes is around $\$ 90$ per ton - far above most estimates of the benefits per ton of $\mathrm{CO}_{2}$ reductions (e.g., Aldy et al., 2010, US IAWG, 2010). ${ }^{25}$ In contrast, the average cost is negative $\$ 12$ per ton when efficiency gains from the revenue-recycling effect are fully exploited (without even including any climate benefits). In our compromise cases where the carbon policy is neither regressive nor progressive the average cost per ton reduced is $\$ 18$ to $\$ 42$.

Given these tradeoffs, and the potentially huge consequences for both efficiency and distribution, more attention should be paid to the use of revenue when analyzing carbon policy. And future research on creative policy designs that balance efficiency, distribution, and political feasibility could be highly valuable.

\footnotetext{
${ }^{25}$ Nonetheless, there are many arguments for moving ahead with a cap-and-trade program, even if it fails a narrowly defined cost-benefit test in the early years. For example, the benefit to cost ratio could easily become favorable over time as the policy is tightened and a greater share of policy rents are used in efficiency-enhancing ways; putting a price on carbon could have important long run benefits in terms of encouraging clean technology development; and action by the United States on climate policy could help to spur similar programs in other countries.
} 


\section{Appendix: Analytical Derivations}

\section{Deriving equation (10)}

We follow the usual two-step procedure for obtaining the marginal welfare effects of policy changes. First we solve the household's optimization problem. Then we obtain the welfare effects of a marginal change in the emissions price by totally differentiating the household's indirect utility, accounting for the household's behavior, and changes in prices, taxes, and lumpsum income. Finally, we integrate over marginal welfare effects to obtain the effects of nonmarginal policy changes.

Household Optimization. From (1)-(3), the optimization problem for household group $i$ is given by:

$$
\begin{aligned}
& V_{i}\left(p_{E}, p_{F}, p_{C}, t_{i}, G_{i}, \pi_{i}\right)= \\
& \underbrace{\operatorname{Max}}_{X_{i E}, X_{i F}, X_{i C}, L_{i}} u_{i}\left(X_{i E}, X_{i F}, X_{i C}, L_{i}, G^{P U B}\right)+\lambda_{i}\left[\left(1-t_{i}\right) \Gamma_{i}+G_{i}+\pi_{i}-\sum_{j} p_{j} X_{i j}\right]
\end{aligned}
$$

where $V_{i}($.$) denotes the indirect utility function and \lambda_{i}$ is the marginal utility of income. Using the definition of taxable income in (3a), this optimization yields the first order conditions, demand, and labor supply functions:

$$
\begin{aligned}
& \frac{\partial u_{i}}{\partial X_{i E}}=\lambda_{i} p_{E}, \quad \frac{\partial u_{i}}{\partial X_{i F}}=\lambda_{i} p_{F}\left(1-t_{i}\right), \quad \frac{\partial u_{i}}{\partial X_{i C}}=\lambda_{i} p_{C}, \frac{\partial u_{i}}{\partial L_{i}}=\lambda_{i}\left(1-t_{i}\right) w_{i}, \\
& X_{i j}=X_{i j}\left(p_{E}, p_{F}, p_{C}, t_{i}\right), \quad L_{i}=L_{i}\left(p_{E}, p_{F}, p_{C}, t_{i}\right)
\end{aligned}
$$

To manipulate the analytical derivations below, we obtain the following additional expressions by totally differentiating the expression in (A1) with respect to arguments of the indirect utility function, and using the conditions in (A2). This gives:

$$
\frac{\partial V_{i}}{\partial p_{j}}=-\lambda_{i} X_{i j}, \frac{\partial V_{i}}{\partial t_{i}}=-\lambda_{i} \Gamma_{i}, \quad \frac{\partial V_{i}}{\partial G_{i}}=\frac{\partial V_{i}}{\partial \pi_{i}}=\lambda_{i}
$$

\section{Welfare Effects of Marginal Policy Changes}

Aggregate welfare is given by the sum of individual utilities, $\sum_{i} V_{i}$. Totally differentiating this with respect to a change in the emissions price, and expressing in monetary units, gives: 


$$
\sum_{i} \frac{1}{\lambda_{i}} \frac{d V_{i}}{d \tau}=\sum_{i} \frac{1}{\lambda_{i}}\left[\sum_{j} \frac{\partial V_{i}}{\partial p_{j}} \frac{d p_{j}}{d \tau}+\frac{\partial V_{i}}{\partial t_{i}} \frac{\partial t_{i}}{\partial \tau}+\frac{\partial V_{i}}{\partial G_{i}} \frac{d G_{i}}{d \tau}+\frac{\partial V_{i}}{\partial \pi_{i}} \frac{d \pi_{i}}{d \tau}\right]
$$

Next, we discuss expressions for some of the individual terms in (A4).

First consider $d p_{j} / d \tau$. Differentiating (5) with respect to $\tau$ gives:

$$
\frac{d p_{H}}{d \tau}=\left(\tau-c^{\prime}\right) \frac{d z}{d \tau}+z
$$

However the first term cancels, assuming that firms equate marginal abatement costs $c^{\prime}$ to the emissions tax. Differentiating (4) with respect to $\tau$, and using (A5), gives:

$$
\frac{d p_{j}}{d \tau}=\rho_{j} z
$$

Using (A6), (A3) and (6), the first term in (A4) simplifies as follows:

$$
\sum_{i} \frac{1}{\lambda_{i}} \sum_{j} \frac{\partial V_{i}}{\partial p_{j}} \frac{d p_{j}}{d \tau}=-Z
$$

Next, take the second and third terms in (A4), and substitute using (A3) to give:

$$
\sum_{i}\left\{\frac{\partial V_{i}}{\partial t_{i}} \frac{\partial t_{i}}{\partial \tau}+\frac{\partial V_{i}}{\partial G_{i}} \frac{d G_{i}}{d \tau}\right\} \frac{1}{\lambda_{i}}=\sum_{i}\left\{\frac{d G_{i}}{d \tau}-\Gamma_{i} \frac{d t_{i}}{d \tau}\right\}
$$

Now we totally differentiate the government budget constraint in (8) with respect to $\tau$, holding $G^{P U B}$ constant but allowing $t_{i}$ and $G_{i}$ to vary, where $d t_{i} / d \tau=d t / d \tau$. This gives, after expressing changes in $Z$ as a total differential:

(A9) $\sum_{i} \frac{d G_{i}}{d \tau}=(1-\phi)\left(Z+\tau \frac{d Z}{d \tau}+\sum_{i} t_{i} \frac{\partial \Gamma_{i}}{\partial \tau}\right)+\sum_{i}\left(\Gamma_{i}+t_{i} \frac{\partial \Gamma_{i}}{\partial t_{i}}\right) \frac{d t}{d \tau}+\sum_{i} t_{i} \frac{\partial \Gamma_{i}}{\partial G_{i}} \frac{d G_{i}}{d \tau}$

From the definition of the marginal excess burden in (10b):

(A10) $\sum_{i}\left(\Gamma_{i}+t_{i} \frac{\partial \Gamma_{i}}{\partial t_{i}}\right)=\frac{\sum_{i} \Gamma_{i}}{1+M E B}$

Substituting (A10) in (A9), multiplying through by $1+M E B$ and subtracting $\sum_{i} \Gamma_{i} d t / d \tau$ gives:

$$
\text { (A11) } \begin{aligned}
& \sum_{i}\left(\frac{d G_{i}}{d \tau}-\Gamma_{i} \frac{d t}{d \tau}\right)=(1+M E B)(\left.\left(Z+\tau \frac{d Z}{d \tau}\right)(1-\phi)+\sum_{i} t_{i} \frac{\partial \Gamma_{i}}{\partial \tau}\right) \\
&+(1+M E B) \sum_{i} t_{i} \frac{\partial \Gamma_{i}}{\partial G_{i}} \frac{d G_{i}}{d \tau}-\quad \sum-
\end{aligned}
$$


Finally, from differentiating (7) with respect to $\tau$, and using (A3), the last term in (A4) can be expressed

(A12) $\sum_{i} \frac{1}{\lambda_{i}} \frac{\partial V_{i}}{\partial \pi_{i}} \frac{d \pi_{i}}{d \tau}=\phi\left(Z+\tau \frac{d Z}{d \tau}\right)$

where we have used $\sum_{i} \theta_{i}=1$.

Substituting (A7), (A8), (A11) and (A12) in (A4), and expressing utility losses as a positive number (i.e., welfare cost) gives:

(A13) $-\sum_{i} \frac{1}{\lambda_{i}} \frac{d V_{i}}{d \tau}=-\tau \frac{d Z}{d \tau}-M E B \cdot\left[(1-\phi)\left(Z+\tau \frac{d Z}{d \tau}\right)-\sum_{i} \frac{d G_{i}}{d \tau}\right]$

$$
-(1+M E B) \cdot \sum_{i} t_{i} \frac{\partial \Gamma_{i}}{\partial \tau}-(1+M E B) \cdot \sum_{i} t_{i} \frac{\partial \Gamma_{i}}{\partial G_{i}} \frac{d G_{i}}{d \tau}
$$

Welfare Effects of Non-Marginal Policy Changes

Integrating the first term in (A13) between 0 and $\tau$, assuming $d Z / d \tau$ is constant, gives:

(A14) $-\frac{d Z}{d \tau} \frac{\tau^{2}}{2}$

Again, given $d Z / d \tau$ is constant, $-(d Z / d \tau) \tau=Z_{0}-Z$. Hence we obtain $W C^{H T}$ in (10a).

We take the $M E B$ as constant over the relevant range, which is reasonable given that proportional changes in income tax rates are relatively small. Integrating marginal emissions tax revenue $(1-\phi)(Z+\tau \cdot d Z / d \tau)$ over an emissions tax rising from 0 to $\tau$ simply gives revenue raised by the tax, $(1-\phi) \tau Z$. And integrating the marginal change in the transfer payment for household group $i$ over the tax increase simply gives the total change in transfer payment $G_{i}-G_{i}^{0}=\Delta G_{i}$. Hence we obtain $W C^{R R}$ in (10a). 
From the third component of (A13), $\partial \Gamma_{i} / \partial \tau=\left(\partial \Gamma_{i} / \partial \bar{p}\right)(\partial \bar{p} / \partial \tau)$. Taking a small change in the emissions price this expression becomes $\left(\partial \Gamma_{i} / \partial \bar{p}\right) \Delta \bar{p}$. Hence we obtain the first expression for $W C^{T I}$ in (10a).

Substituting expressions for $\eta_{i}^{\bar{p}}$ and $\alpha_{i}^{T}$ from (10b), gives:

(A15) $W C^{T I}=(1+M E B) \sum_{i} \alpha_{i}^{T} t_{i} \eta_{i}^{\bar{p}} \Delta \bar{p} \sum_{i} I_{i}$

where the general price level is normalized to unity. The burden of the emissions price $\tau(Z+\Delta Z / 2)$ is fully passed forward into higher product prices, therefore $\Delta \bar{p}=\tau(Z+\Delta Z / 2) / \sum_{i j} X_{i j}$. Making this substitution and $\sum_{i j} X_{i j}=\sum_{i} I_{i}$ in (A15) gives the second expression for $W C^{T I}$ in (10a).

Finally, again if we approximate by taking $t_{i}$ and $\partial \Gamma_{i} / \partial G_{i}$ as constant over the relevant range, then integrating over the last term in (A13) gives

(A16) $-(1+M E B) \cdot \sum_{i} t_{i} \frac{\partial \Gamma_{i}}{\partial G_{i}} \Delta G_{i}$

Substituting out $\partial \Gamma_{i} / \partial G_{i}=\partial \Gamma_{i} / \partial I_{i}$ using the taxable income elasticity with respect to income in (10b), gives the last expression $W C^{I N C}$ in (10a).

\section{Deriving equation (11)}

Equation (11) comes from the effect on utility from small changes in each of the arguments of $V_{i}($.$) in equation (A1), after substituting (A3), and dividing by \lambda_{i} I_{i}$. 


\section{References}

Aldy, Joseph, Alan J. Krupnick, Richard G. Newell, Ian W.H. Parry and William A. Pizer, 2010. "Designing Climate Mitigation Policy.” Journal of Economic Literature, forthcoming.

Blundell, Richard and Thomas MaCurdy, 1999. "Labor Supply: A Review of Alternative Approaches." in Handbook of Labor Economics, Volume III, O. Ashenfelter and D. Card (eds). New York: North-Holland.

Bovenberg, A. Lans, and Lawrence H. Goulder, 2001. "Neutralizing the Adverse Industry Impacts of $\mathrm{CO} 2$ Abatement Policies: What Does It Cost?" In Behavioral and Distributional Effects of Environmental Policy. C. Carraro and G. Metcalf ed. Chicago: University of Chicago Press, 45-85.

Burtraw, Dallas, Richard Sweeney, and Margaret A. Walls, 2009. "The Incidence of U.S. Climate Policy: Alternative Uses of Revenues from a Cap-and-Trade Auction". National Tax Journal 62: 497-518.

Dinan, Terry M. and Diane L. Rogers, 2002. "Distributional Effects of Carbon Allowance Trading: How Government Decisions Determine Winners and Losers." National Tax Journal 55: 199-222.

Fullerton, Don and Gilbert Metcalf, 2001. "Environmental Controls, Scarcity Rents, and PreExisting Distortions." Journal of Public Economics 80: 249-67.

Goulder, Lawrence H., 1995. "Environmental Taxation and the 'Double Dividend': A Reader's Guide." International Tax and Public Finance 2: 157-183.

Goulder, Lawrence H., Ian W. H. Parry, Roberton C. Williams III, and Dallas Burtraw, 1999. "The Cost-Effectiveness of Alternative Instruments for Environmental Protection in a SecondBest Setting," Journal of Public Economics, 1999, 72:329-360

Grainger, Corbett A. and Charles D. Kolstad, 2010. "Who Pays a Price on Carbon?" Environmental and Resource Economics 46: 359-376.

Hassett, Kevin A., Aparna Mathur, and Gilbert E. Metcalf, 2007. "The Incidence of a U.S. Carbon Tax: A Lifetime and Regional Analysis.” NBER Working Paper 13554.

Kaplow, Louis, 2004. "On the (Ir)Relevance of Distribution and Labor Supply Distortion to Government Policy.” Journal of Economic Perspectives 18: 159-175.

Krupnick, Alan J., Ian W.H. Parry, Margaret Walls, Tony Knowles and Kristin Hayes, 2010. Toward a New National Energy Policy: Assessing the Options. Resources for the Future and National Energy Policy Institute, Washington, DC. 
Parry, Ian W.H., and Antonio M. Bento, 2000, “Tax Deductions, Environmental Policy, and the "Double Dividend" Hypothesis," Journal of Environmental Economics and Management 39: 6796.

Parry, Ian W.H., 2004. “Are Emissions Permits Regressive?" Journal of Environmental Economics and Management 47:364-387.

Parry, Ian W.H., 2005. "Fiscal Interactions and the Costs of Pollution Control from Electricity." RAND Journal of Economics 36: 849-869.

Pizer, William A., 2003. "Combining Price and Quantity Controls to Mitigate Global Climate Change." Journal of Public Economics 85: 409-434.

Saez, Emanuel, Joel Slemrod, and Seth Giertz, 2009. "The Elasticity of Taxable Income with Respect to Marginal Tax Rates: A Critical Review.” NBER Working Paper no. 15012.

Schöb, Ronnie, 2006. “The Double Dividend Hypothesis of Environmental Taxes: A Survey.” In $\mathrm{H}$. Folmer and T. Tietenberg (eds.), The International Yearbook of Environmental and Resource Economics 2005/2006. Edward Elgar, Cheltenham, United Kingdom.

Smith, Anne E., Martin E. Ross, and W. David Montgomery, 2002. "Implications of Trading Implementation Design for Equity-Efficiency Tradeoffs in Carbon Permit Allocations." Working paper. Washington, D.C.: Charles River Associates.

Sijm, Jos, Karsten Neuhoff and Yihsu Chen, 2006. " $\mathrm{CO}_{2}$ Cost Pass-Through and Windfall Profits in the Power Sector." Climate Policy 6: 49-72.

US IAWG, 2010. Technical Support Document: Social Cost of Carbon for Regulatory Impact Analysis Under Executive Order 12866. Interagency Working Group on Social Cost of Carbon, United States Government, Washington, DC.

Williams, Roberton C., 2009a. "An Estimate of the Second-Best Optimal Gasoline Tax, Considering Both Efficiency and Equity.” Working paper, University of Maryland.

Williams, Roberton C., 2009b. "Distribution, Distortionary Taxation, and the Evaluation of Public Goods.” Working paper, University of Maryland. 
Table 1. Summary of Baseline Data

(projections for year 2020 with monetary data in year 2008 dollars)

\begin{tabular}{|c|c|c|c|c|c|c|}
\hline \multirow[t]{2}{*}{ Household data } & \multicolumn{5}{|c|}{ Income quintile } & \multirow[t]{2}{*}{ Average } \\
\hline & 1 & 2 & 3 & 4 & 5 & \\
\hline Income, \$ & 11,307 & 22,882 & 46,638 & 81,467 & 181,626 & 68,784 \\
\hline Consumption, \$ & 22,566 & 34,187 & 47,835 & 66,202 & 108,573 & 55,873 \\
\hline \multicolumn{7}{|l|}{ Burden of carbon tax } \\
\hline as percentage of income & $6.03 \%$ & $4.27 \%$ & $2.71 \%$ & $1.87 \%$ & $1.16 \%$ & $1.59 \%$ \\
\hline as percentage of consumption & $3.02 \%$ & $2.86 \%$ & $2.64 \%$ & $2.31 \%$ & $1.94 \%$ & $1.96 \%$ \\
\hline Fraction of stockholder wealth owned & $2.63 \%$ & $8.92 \%$ & $8.63 \%$ & $19.99 \%$ & $59.84 \%$ & \\
\hline \multirow[t]{3}{*}{ Lump-sum transfer component of tax, $\$$} & 4,048 & 6,762 & 9,404 & 11,909 & 7,949 & 8,014 \\
\hline & \multicolumn{5}{|c|}{ Consumption quintile } & Average \\
\hline & 1 & 2 & 3 & 4 & 5 & \\
\hline Income, \$ & 18,204 & 35,476 & 53,203 & 82,719 & 145,079 & 66,936 \\
\hline Consumption, \$ & 19,253 & 34,605 & 49,644 & 70,428 & 126,173 & 60,020 \\
\hline \multicolumn{7}{|l|}{ Burden of carbon tax } \\
\hline as percentage of income & $3.27 \%$ & $2.74 \%$ & $2.27 \%$ & $1.87 \%$ & $1.54 \%$ & $1.64 \%$ \\
\hline as percentage of consumption & $3.09 \%$ & $2.81 \%$ & $2.43 \%$ & $2.20 \%$ & $1.77 \%$ & $1.83 \%$ \\
\hline Fraction of stockholder wealth owned & $1.60 \%$ & $3.30 \%$ & $12.85 \%$ & $24.63 \%$ & $57.62 \%$ & \\
\hline Lump-sum transfer component of tax, $\$$ & 3,453 & 7,716 & 11,085 & 13,743 & 10,314 & 9,262 \\
\hline
\end{tabular}

\begin{tabular}{lccccccc} 
& \multicolumn{4}{c}{ Income or Consumption quintile } & \multirow{2}{*}{ Average } \\
\cline { 2 - 6 } & 1 & 2 & 3 & 4 & 5 & \\
\hline Income tax rate & $17 \%$ & $33 \%$ & $40 \%$ & $44 \%$ & $41 \%$ & & $40 \%$ \\
Taxable income elasticities & & & & & & \\
$\quad$ with respect to taxes & 0.20 & 0.22 & 0.25 & 0.28 & 0.35 & 0.31 \\
$\quad$ with respect to price level & 0.15 & 0.15 & 0.15 & 0.15 & 0.15 & 0.15 \\
$\quad$ with respect to income & -0.20 & -0.20 & -0.20 & -0.20 & -0.20 & -0.20 \\
& & & & & & \\
\hline
\end{tabular}

\section{Other data}

Marginal excess burden of taxation $\quad 0.27$

$\mathrm{BAU} \mathrm{CO}_{2}$ emissions, billion tons $\quad 6.0$

Emissions price, $\$ /$ ton $\quad 33$

Reduction in emissions from BAU $\quad 9.0 \%$

Policy rents/revenues, \$billion $\quad 180$

Source. See text.

Note that averages differ slightly between the income and consumption quintile cases, due to dropping households with consumption under $\$ 7,500$ 
Figure 1. Decomposition of Efficiency Costs under Alternative Policies

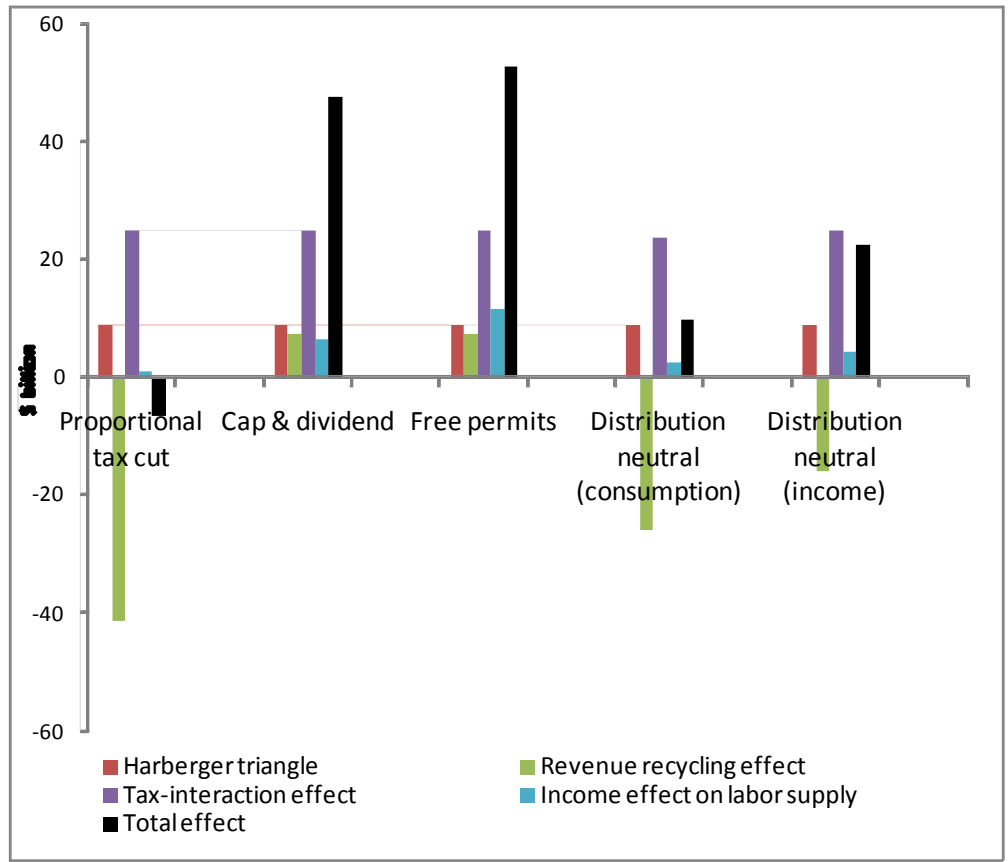


Figure 2. Decomposition of Net Burden by Income Quintile under Alternative Policies

(a) Proportional tax cut

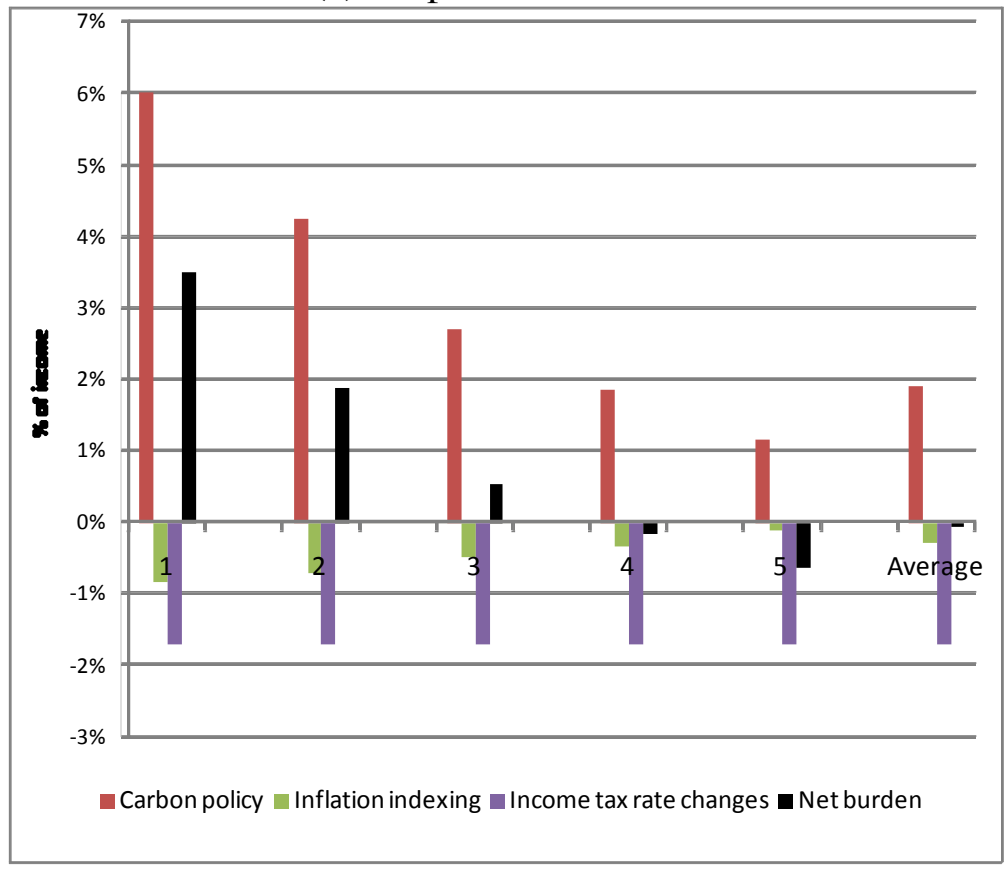

(b) Cap-and-Dividend




(c) Free Permit Allocation

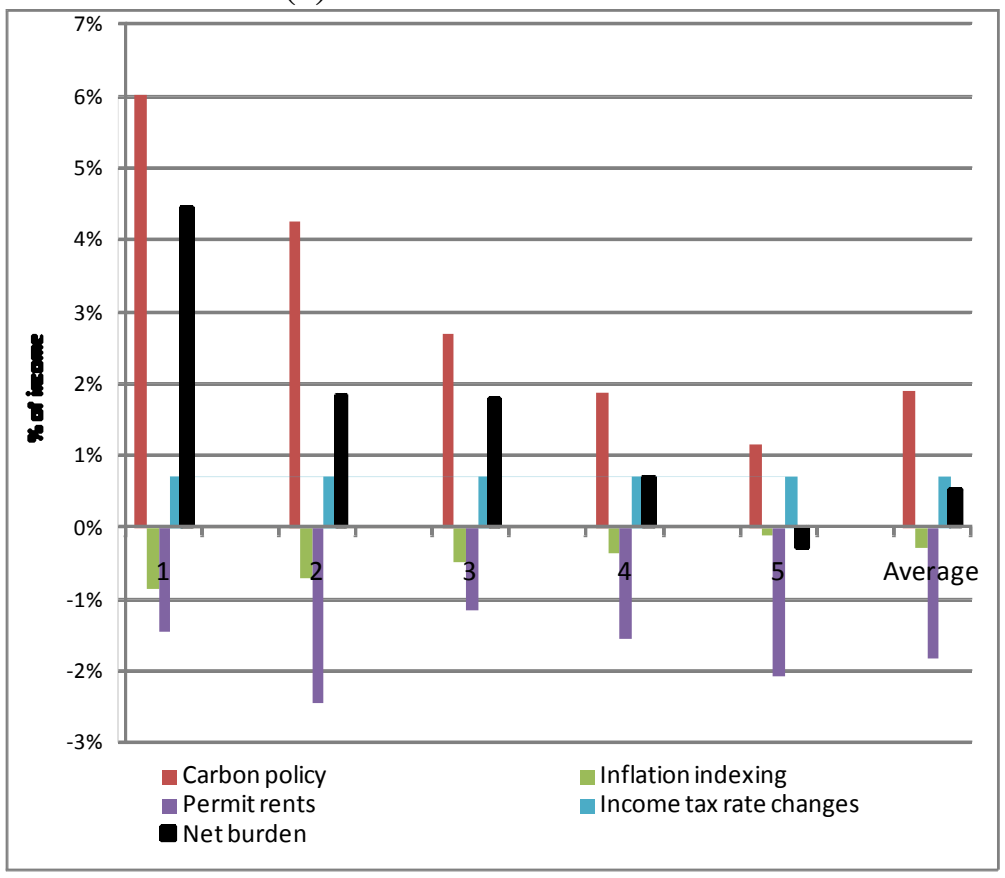

(d) Distribution-Neutral

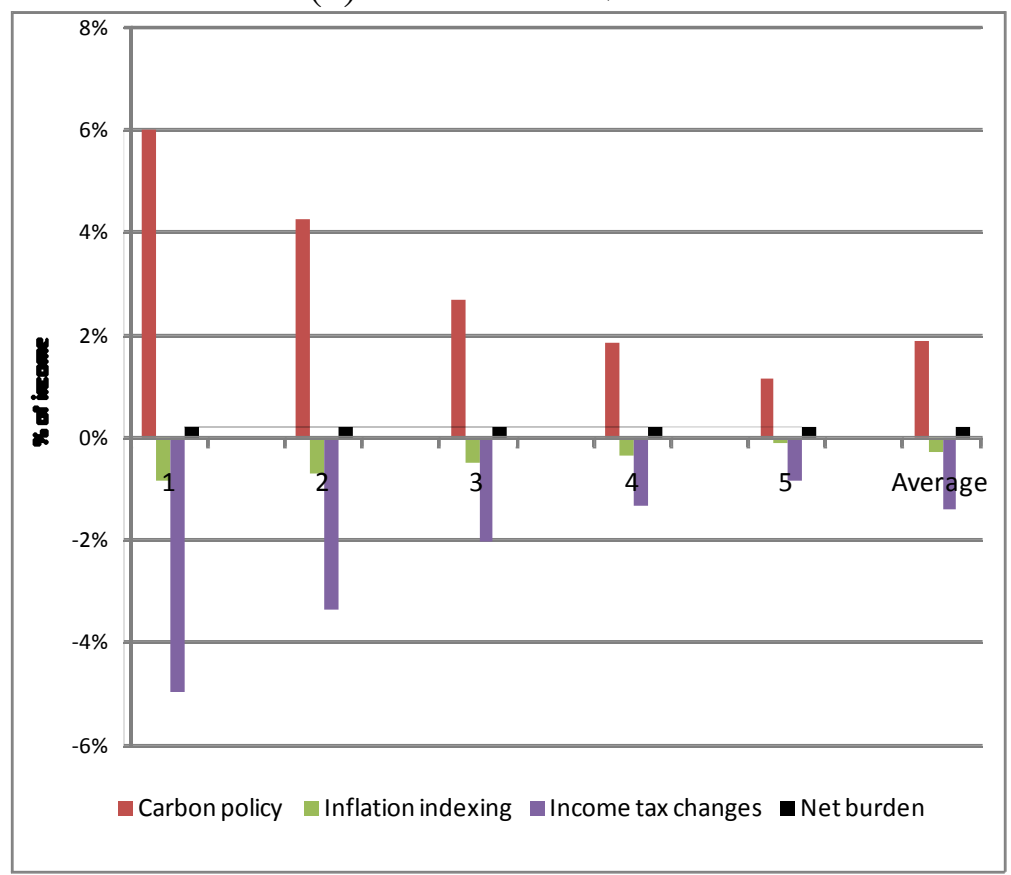


Figure 3. Decomposition of Net Burden by Consumption Quintile under Alternative Policies

(a) Proportional tax cut

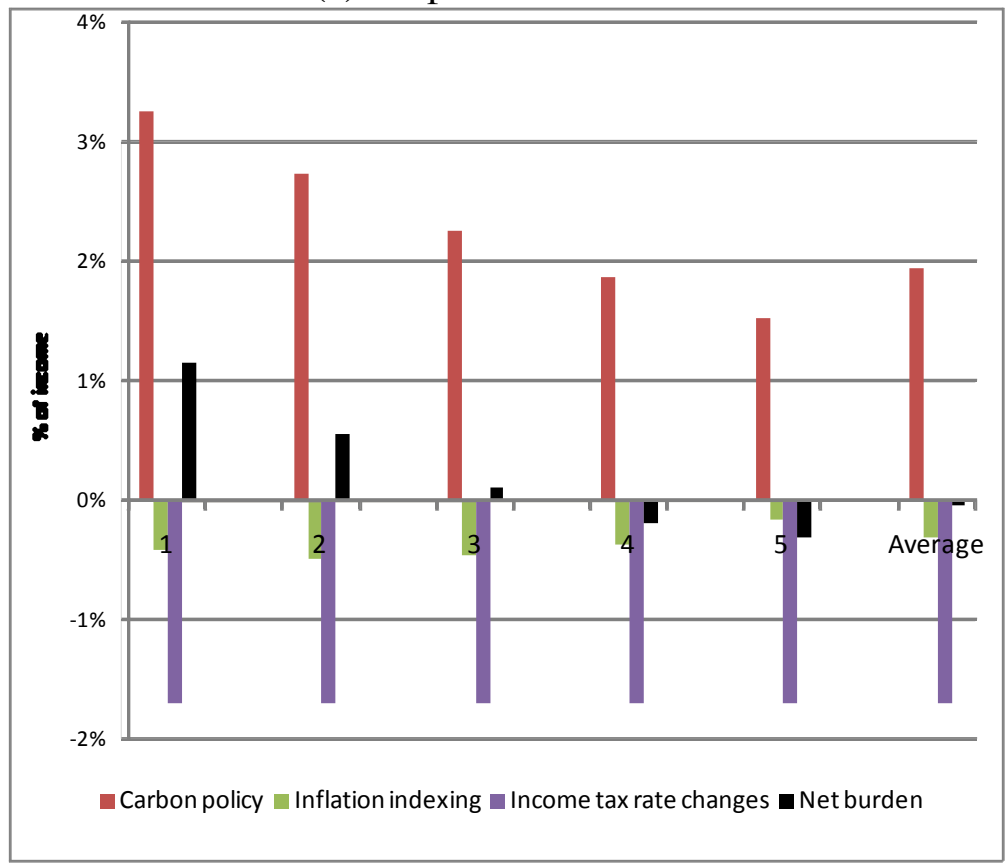

(b) Cap-and-Dividend

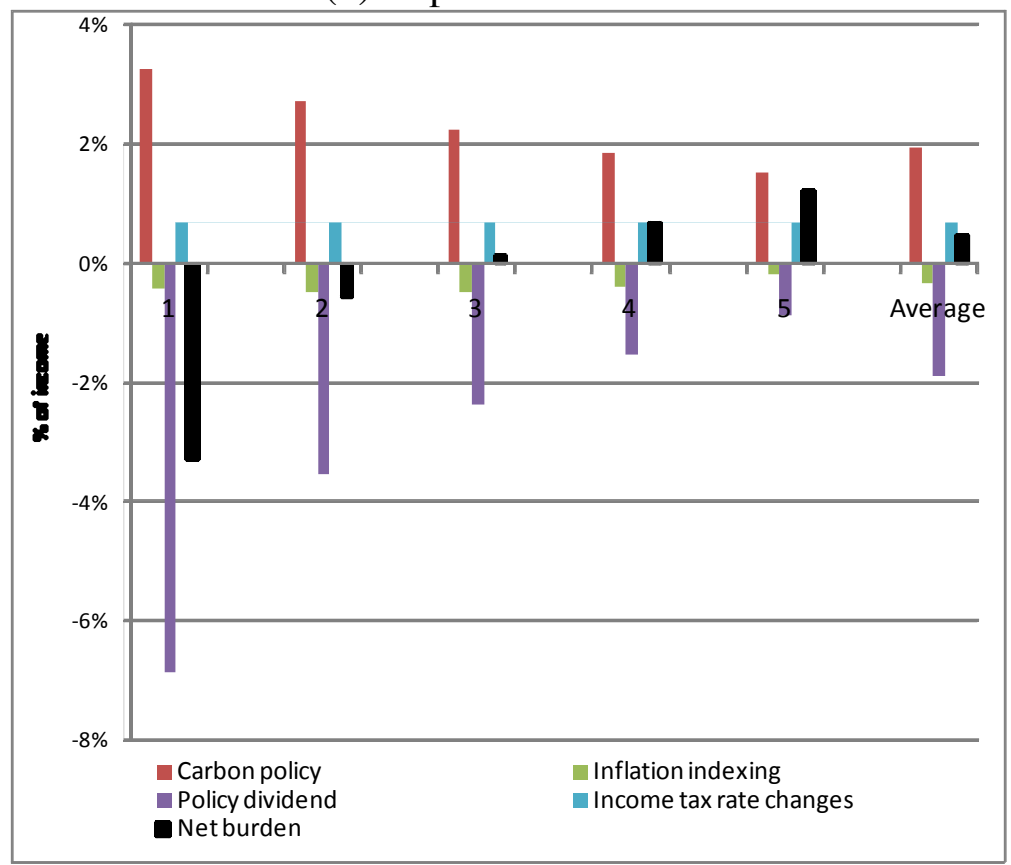


(c) Free Permit Allocation

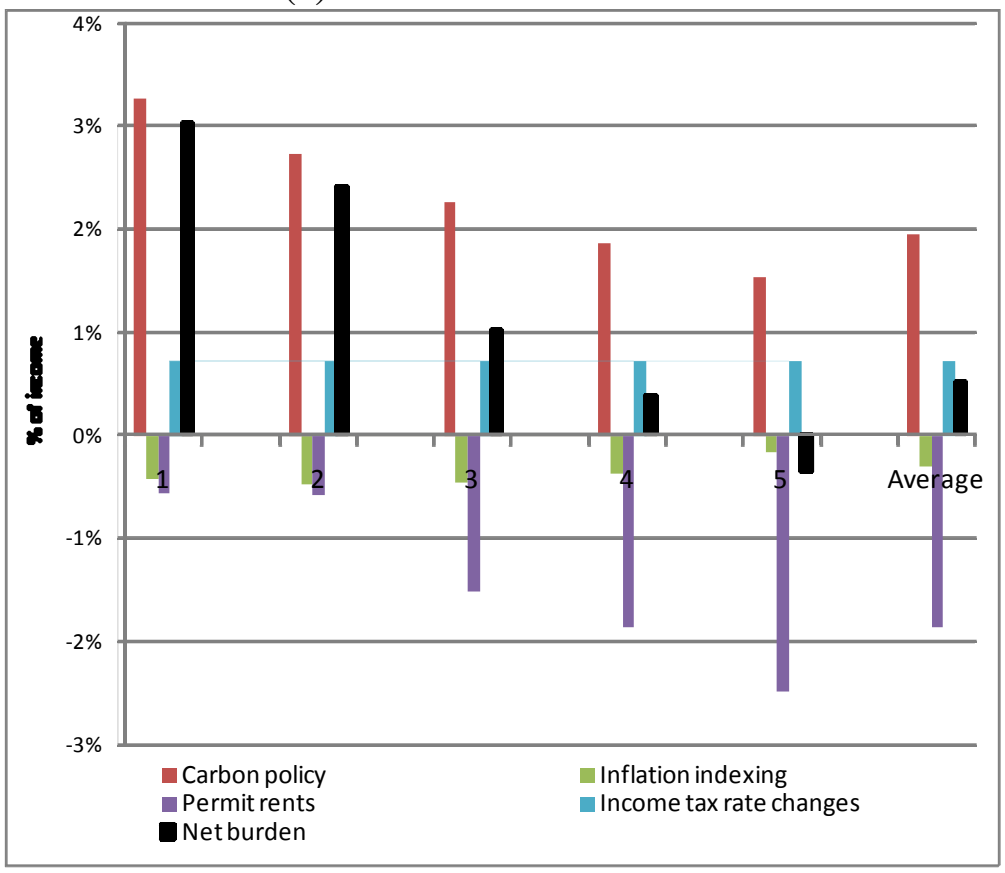

(d) Distribution-Neutral

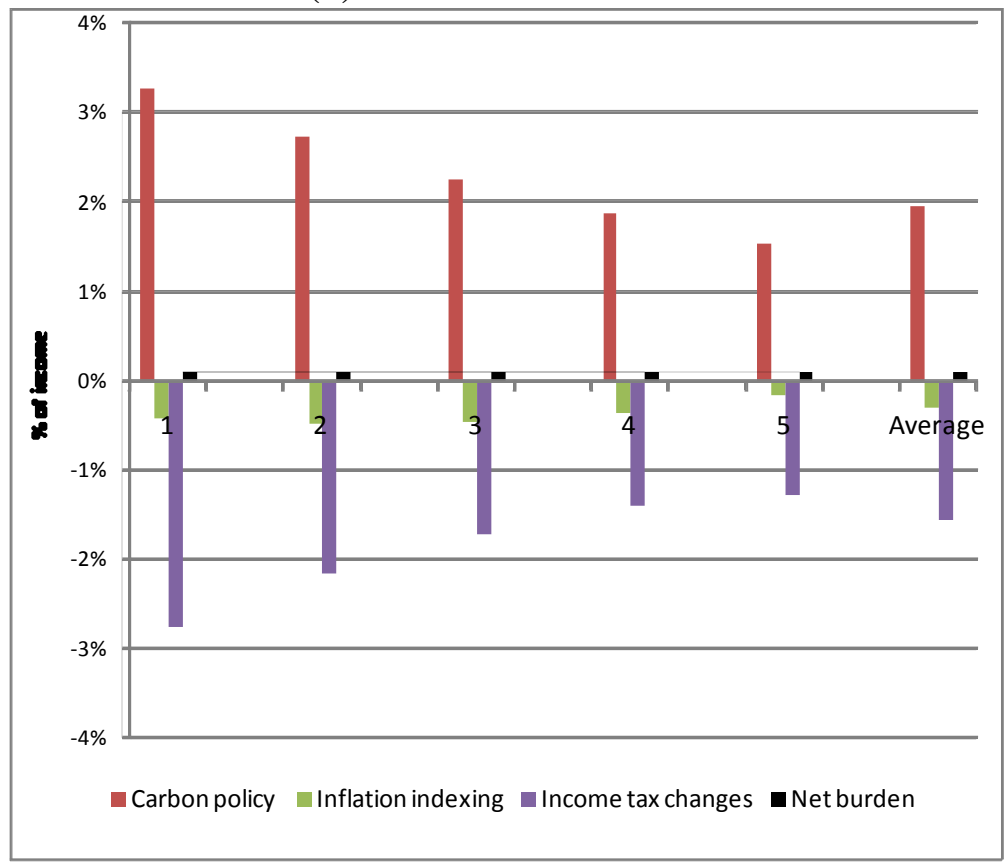

